Trauma Surgery \& Acute Care Open

\title{
Minimally invasive approach to low-velocity penetrating extraperitoneal rectal trauma
}

\author{
Megan Melland-Smith, ${ }^{1}$ Tyler R Chesney, ${ }^{1}$ Shady Ashamalla, ${ }^{1,2}$ Fred Brenneman ${ }^{1,2}$
}

\begin{abstract}
- Additional material is published online only. To view please visit the journal online (http://dx.doi.org/10.1136/ tsaco-2019-000396).

${ }^{1}$ General Surgery, University of Toronto, Toronto, Ontario, Canada

${ }^{2}$ Sunnybrook Health Sciences Centre, Toronto, Ontario, Canada

Correspondence to Dr Megan Melland-Smith, General Surgery, University of Toronto, Toronto, ON M5S, Canada; megan.mellandsmith@ucdconnect.ie
\end{abstract}

Received 9 October 2019 Revised 12 November 2019 Accepted 8 December 2019

\section{(C) Author(s) (or their} employer(s)) 2020. Re-use permitted under CC BY-NC. No commercial re-use. See rights and permissions. Published by BMJ.

To cite: Melland-Smith $\mathrm{M}$, Chesney TR, Ashamalla S, et al. Trauma Surg Acute Care Open 2020;5:e000396.

\section{ABSTRACT}

Unlike intraperitoneal colorectal injuries, the standard of care for extraperitoneal rectal trauma includes a diverting colostomy due to relative inaccessibility of these injuries for primary repair. New technologies to enhance access to the extraperitoneal rectum have gained increasing use in benign and malignant rectal disease. We present two cases of low-velocity penetrating extraperitoneal rectal trauma. In both cases, a transanal minimally invasive surgery (TAMIS) approach was used to access, and primarily repair, full-thickness rectal lacerations. These patients were successfully managed without a colostomy and without complication. TAMIS enables access to distal rectal injuries, facilitating primary repair and bringing the management of extraperitoneal rectal injuries in line with intraperitoneal injuries, with the potential to avoid fecal diversion.

\section{INTRODUCTION}

The management of rectal trauma has evolved substantially, guided largely by experiences in military settings. ${ }^{1}$ These experiences led to standard recommendations for all traumatic rectal injuries combining fecal diversion, distal rectal washout, presacral drainage, and rectal injury repair when feasible. ${ }^{1-3}$ Unlike in the military setting, penetrating rectal injuries in the civilian setting are more commonly low-velocity and less destructive injuries questioning the role of the military approach in this setting. ${ }^{4}$ The management of intraperitoneal rectal injuries, which are accessible transabdominally, are guided by the same principles as used for colonic injuries, which often includes primary repair without diversion. ${ }^{5}$ In contrast, penetrating extraperitoneal rectal injuries are difficult to access and contemporary guidelines recommend proximal diversion, no presacral drainage, and no distal rectal washout. ${ }^{4}$ Transabdominal approaches can only offer fecal diversion for these inaccessible injuries. Optimizing access to extraperitoneal rectal injuries may enable primary repair and avoid the need for diversion. Transanal minimally invasive surgery (TAMIS) is a new technology with increasing applications in benign and malignant rectal disease. ${ }^{6}$ TAMIS makes use of single-incision laparoscopic-type access port placed transanally to allow visualization and use of laparoscopic instruments for advanced endoluminal procedures throughout the length of the rectum. ${ }^{7}$ We discuss two cases of low-velocity penetrating extraperitoneal rectal trauma in which we used TAMIS to allow direct visualization and access to the extraperitoneal rectal injuries enabling primary closure and avoidance of a diverting stoma.

\section{Case presentations}

Case 1. A 23-year-old male presented following an assault incident with hematuria and rectal bleeding from transanal penetration with a steel rod. In the trauma bay, the patient was hemodynamically stable with a negative focused assessment with sonography in trauma (FAST) examination. The primary and secondary survey identified gross hematuria and rectal bleeding. Rigid sigmoidoscopy at the bedside identified no obvious defect in the rectal wall, but visualization was obscured by clotted blood. CT imaging revealed perirectal air with no intraperitoneal fluid, and CT cystogram revealed posterior extraperitoneal bladder injury (figure 1). The patient remained hemodynamically stable and was taken to the operating room. Exploratory laparoscopy was conducted initially. The sigmoid colon was mobilized with a small volume blood-tinged fluid in the pelvis, but no intraperitoneal rectal injury or enteric contents identified. An intraperitoneal bladder injury was identified characterized as a $1 \mathrm{~cm}$ defect at the dome of the bladder. This bladder injury was suture repaired laparoscopically. A TAMIS approach was then used to identify the extraperitoneal rectal injury. A full-thickness anterior extraperitoneal rectal laceration was identified $5 \mathrm{~cm}$ from the anal verge affecting less than $50 \%$ of the circumference of the lumen without devitalized tissue (Rectal Injury Score, RIS, II). ${ }^{8}$ The rectum was irrigated and the laceration was repaired transanally with a running self-locking suture. No debridement was required. The extraperitoneal bladder injury was treated conventionally with long-term in-dwelling Foley catheterization. Given the location of the injuries, the presumed trajectory of the rod was through the anal canal, through the anterior rectal wall, through the adjacent bladder in an extraperitoneal position, and then to the bladder dome intraperitoneally. The patient's postoperative course was uncomplicated, and he was discharged home well on postoperative day 11 .

Case 2. A 17-year-old-male presented with a stab wound to the right gluteal region. In the trauma bay, the patient was hemodynamically stable, and FAST examination result was negative. On digital rectal examination, gross blood was encountered. The primary and secondary survey identified only rectal bleeding. CT imaging revealed perirectal air with no other injuries identified. He was taken to the operating room with a planned TAMIS approach for repair (figure 2). An RIS II full-thickness rectal laceration was identified at the right posterolateral aspect of the rectum, $7 \mathrm{~cm}$ from the anal verge. On the opposite rectal wall, there was a smaller $1 \mathrm{~cm}$ full-thickness laceration. Rigid sigmoidoscopy up to 


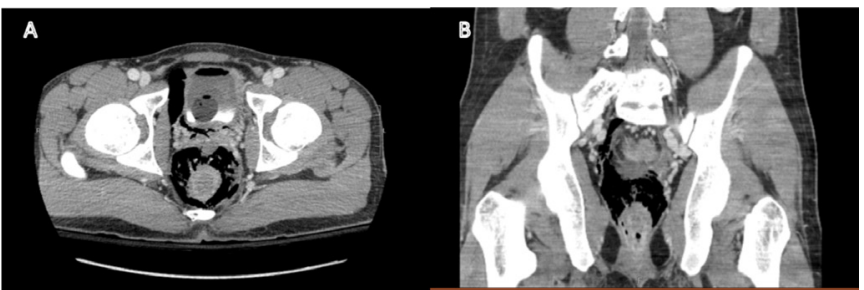

Figure $1 \mathrm{CT}$ image demonstrating air in the perirectal space and intravesical air secondary to traumatic penetration with a steel rod; (A) axial view, (B) coronal view.

$20 \mathrm{~cm}$ identified no other injuries and there was no evidence of devascularized tissue. No debridement was required. The rectum was thoroughly irrigated and both lacerations were closed transanally using self-locking sutures (online supplementary digital content). Postoperatively, antibiotics were given for a total duration of 7 days. He was having bowel movements by postoperative day 2 and was discharged home well on postoperative day 3 .

\section{Outcomes and follow-up}

TAMIS enabled successful transanal visualization and endoluminal primary repair of low-velocity non-destructive penetrating extraperitoneal rectal injuries. The injuries were irrigated until clean. Barbed self-locking suture was used to reapproximate the wound edges. Proximal diversion was not required. Broadspectrum antibiotics were used perioperatively. If there is no other indication for immediate laparotomy, diagnostic laparoscopy can be used in combination with the transanal approach. Postoperatively there were no complications, and both patients were successfully discharged with normal bowel function.

\section{DISCUSSION}

While contemporary guidance for the management of inaccessible extraperitoneal penetrating rectal trauma recommends proximal fecal diversion, the use of TAMIS techniques enabled access to these injuries for primary repair and the avoidance of diverting stomas.

Colostomies in patients experiencing traumatic injury are associated with stoma-related complications, as well as psychosocial burden and reduced quality of life. ${ }^{9}$ As such, avoiding unnecessary stomas is important to patients. To avoid pelvic sepsis, diverting stomas certainly have a role in more extensive

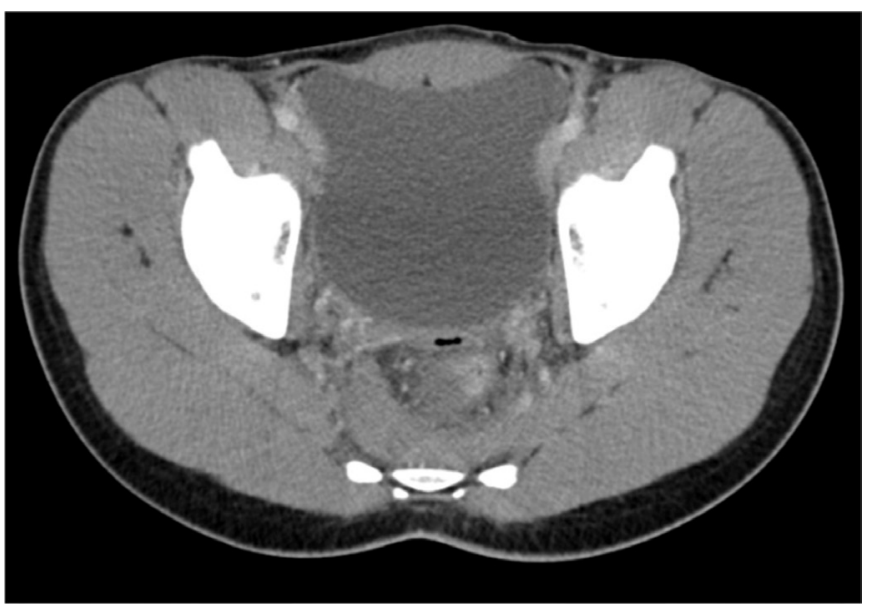

Figure 2 CT image (axial view) demonstrating air in the perirectal space secondary to a right gluteal stab wound. rectal injuries including blunt trauma, destructive pelvic injuries with associated pelvic fractures, and large or devitalized rectal defects when primary repair is not possible. ${ }^{10}$ Unlike in intraperitoneal colorectal injuries where primary repair of nondestructive injuries and resection and primary anastomosis in selected destructive injuries is recommended without diversion, complex dissection to expose extraperitoneal rectal injuries to facilitate primary repair or resection increases morbidity and should not be done ${ }^{1410}$ Using TAMIS as a minimally invasive approach to enhance access to extraperitoneal rectal injuries allows the modern treatment of these injuries to align with that used for intraperitoneal injuries.

Given that proximal diversion is the current recommendation for extraperitoneal rectal trauma, little evidence exists investigating transanal primary repair in the absence of fecal diversion. A retrospective cohort study of 30 patients with extraperitoneal rectal injuries reported that five patients had injuries that were accessible for transanal repair. ${ }^{11}$ These five patients did not require fecal diversion and no complications or deaths were reported. A case report describes the successful primary repair an impalement injury with transanal endoscopic operation without complications. ${ }^{12}$ Our current report adds to the limited literature available on transanal repair of extraperitoneal rectal injuries.

Importantly, the technical advantages of TAMIS to enhance visualization and enable primary repair must be emphasized. TAMIS is a new technique that provides a versatile platform for rectal dissection, local excision of neoplasia, and surgical treatment of multiple benign pathologies. ${ }^{6}$ TAMIS requires a device (GelPOINT Path or SLIS port) for transanal access to allow insufflation. ${ }^{13}$ Pneumorectum is achieved with carbon dioxide insufflation, then standard laparoscopic instruments are used. Standard laparoscopic needle drivers can be used for closure of defects. The TAMIS channel allows circumferential dissection and tissue handling, allows irrigation and suctioning, facilitates endoluminal suturing to allow primary closure of full-thickness rectal defects, and can readily access the lower, mid, and upper rectum. ${ }^{14}$ For defects within $2-3 \mathrm{~cm}$ from the anorectal junction, traditional transanal techniques would better access this area due to the length of the TAMIS port. Chen et al have shown that a combined laparoscopic and transanal endoluminal approach to be a viable option for repair of colorectal anastomotic leaks, particularly when diagnosed early. ${ }^{15}$ These technical advantages as well as reduced wound complications and postoperative morbidity make TAMIS a versatile approach for a wide variety of rectal injuries which our report highlights.

The cases presented here would suggest treating extraperitoneal rectal injuries in a similar manner as intraperitoneal injury with a focus on primary repair without diversion. It is generally accepted that intraperitoneal injuries do not benefit from ostomy formation with the exception of settings where the patient is persistently hypotensive or requiring high volume of transfusions. ${ }^{16}$ Intraperitoneal injuries are treated with resection if the defect spans greater than $25 \%$ circumferential involvement. Previous literature suggests that extraperitoneal injuries involving greater than $25 \%$ circumference and those associated with pelvic fractures, due to the increased risk of pelvic sepsis, would benefit from a diverting ostomy. ${ }^{10}$ Hence, fecal diversion might be considered appropriate for destructive extraperitoneal injuries in the hemodynamically unstable trauma patient. Broadspectrum antibiotic therapy is also consistently used throughout the literature for both intraperitoneal and extraperitoneal rectal injuries and should be a mainstay of treatment in cases where there is no fecal diversion. ${ }^{4}$ 
We describe the use of a TAMIS approach to extraperitoneal rectal injuries that would otherwise be impossible to access for primary repair mandating fecal diversion. However, given the small number of cases in this report, we cannot rule out the possibility of rare adverse events from this approach. Nonetheless, by demonstrating the feasibility of a TAMIS approach for primary repair without diversion, a structured clinical trial can be designed to define outcomes in a larger population.

\section{CONCLUSION}

A TAMIS approach to extraperitoneal penetrating nondestructive rectal trauma in selected cases expands the technical capacity for primary repair of these otherwise inaccessible injuries. Without direct visualization of the injury, transabdominal approaches can only offer proximal diversion. In contrast, TAMIS allows for direct visualization of the injury, accurate assessment of the extent of the injury, irrigation, and closure of extraperitoneal rectal injuries. This allows for the option of avoiding the use of a diverting stoma and brings the approach to extraperitoneal rectal trauma more in line with that of intraperitoneal rectal trauma. We describe the use of TAMIS in two patients with no postoperative morbidity or mortality and the benefit of stoma avoidance. Further clinical trials should investigate this approach to confirm a low rate of complications.

Contributors All authors have satisfied the ICMJE criteria for authorship.

Funding The authors have not declared a specific grant for this research from any funding agency in the public, commercial or not-for-profit sectors.

Competing interests None declared.

Patient consent for publication Not required.

Provenance and peer review Not commissioned; externally peer reviewed.

Open access This is an open access article distributed in accordance with the Creative Commons Attribution Non Commercial (CC BY-NC 4.0) license, which permits others to distribute, remix, adapt, build upon this work non-commercially, and license their derivative works on different terms, provided the original work is properly cited, appropriate credit is given, any changes made indicated, and the use is non-commercial. See: http://creativecommons.org/licenses/by-nc/4.0/.

\section{REFERENCES}

1. Steele SR, Maykel JA, Johnson EK. Traumatic injury of the colon and rectum: the evidence vs dogma. Dis Colon Rectum 2011:54:1184-201.

2. OGILVIE WH. Abdominal wounds in the Western desert. Bull U S Army Med Dep 1946:6:435-45.

3. Lavenson GS, Cohen A. Management of rectal injuries. Am J Surg 1971;122:226-30.

4. Bosarge PL, Como JJ, Fox N, Falck-Ytter Y, Haut ER, Dorion HA, Patel NJ, Rushing $A$, Raff LA, McDonald AA, et al. Management of penetrating extraperitoneal rectal injuries: an Eastern Association for the Surgery of Trauma practice management guideline. J Trauma Acute Care Surg 2016;80:546-51.

5. Weinberg JA, Fabian TC, Magnotti LI, Minard G, Bee TK, Edwards N, Claridge JA, Croce MA. Penetrating rectal trauma: management by anatomic distinction improves outcome. J Trauma 2006:60:508-14.

6. Atallah S, Albert M, Debeche-Adams T, Larach S. Transanal minimally invasive surgery (TAMIS): applications beyond local excision. Tech Coloproctol 2013;17:239-43.

7. Atallah $\mathrm{S}$, Albert M, Larach $\mathrm{S}$. Transanal minimally invasive surgery: a giant leap forward. Surg Endosc 2010;24:2200-5.

8. Moore EE, Cogbill TH, Malangoni M. Scaling system for organ specific injuries Ernest E, 2020.

9. Clemens MS, Heafner TA, Watson JDB, Aden JK, Rasmussen TE, Glasgow SC. Quality of life in United States veterans with combat-related ostomies from Iraq and Afghanistan. Mil Med 2016;181:e1569-74.

10. Navsaria PH, Shaw JM, Zellweger R, Nicol AJ, Kahn D. Diagnostic laparoscopy and diverting sigmoid loop colostomy in the management of civilian extraperitoneal rectal gunshot injuries. Br J Surg 2004;91:460-4.

11. Levine JH, Longo WE, Pruitt C, Mazuski JE, Shapiro MJ, Durham RM. Management of selected rectal injuries by primary repair. Am J Surg 1996;172:575-9.

12. Serra-Aracil X, Gómez-Díaz CJ, Navarro-Soto S, Hidalgo-Rosas JM, Mora-López L. Repair of rectal trauma perforation using transanal endoscopic operation. Colorectal Dis 2012;14:e427-8.

13. de Beche-Adams T, Hassan I, Haggerty S, et al. Clinical Spotlight Review: Transanal Minimally Invasive Surgery (TAMIS). 2017. https://www.sages.org/publications/ guidelines/clinical-spotlight-review-transanal-minimally-invasive-surgery-tamis/.

14. Hussein Q, Artinyan A. Pushing the limits of local excision for rectal cancer: transanal minimally invasive surgery for an upper rectal/rectosigmoid lesion. Ann Surg Oncol 2014;21:1631

15. Chen WT-L, Bansal S, Ke T-W, Chang S-C, Huang Y-C, Kato T, Wang H-M, Fingerhut A. Combined repeat laparoscopy and transanal endolumenal repair (hybrid approach) in the early management of postoperative colorectal anastomotic leaks: technique and outcomes. Surg Endosc 2018;32:4472-80.

16. Lightner AL, Pemberton JH. The role of temporary fecal diversion. Clin Colon Rectal Surg 2017;30:178-83. 